\title{
Evaluation and management of sediments and porous media
}

\author{
Anne M. Hansen ${ }^{1} \cdot$ Nor-Edine Abriak ${ }^{2} \cdot$ Ma. Catalina Alfaro de la Torre ${ }^{3}$ \\ Published online: 6 April 2020 \\ (C) Springer-Verlag GmbH Germany, part of Springer Nature 2020
}

Sediments are unconsolidated material of terrestrial origin produced by alteration of rocks, soils, and organic matter due to the weathering, transport, and deposition in aquatic environments, and of material originating from within water bodies. This material plays a significant role in the physical, chemical, and ecological response of aquatic ecosystems.

Pollutants in water bodies tend to accumulate in sediments. Depending on environmental conditions, such pollutants may be transported with suspended sediments, deposited, or released to the water column and, eventually, be accumulated in biota. Sediments may therefore act as secondary sources of pollutants and hence are an important tool to understand water quality and to investigate past contamination, since the analysis of sediment cores shows contaminants accumulation in different periods of time.

Different methods exist to recover contaminated water bodies and improve ecological quality, fisheries, and water for recreation and for diverse supply systems. These methods include treatments to reduce external contaminant loads coming from the hydrological basin and technologies that control internal contaminant loads. The release or internal load of contaminants accumulated in sediment makes it essential to apply technologies within water bodies. For the selection of remediation technologies, the origin of the problem must be quantitatively understood, including the determination of pollutant loads, from both external and internal sources.

Responsible editor: Philippe Garrigues

Anne M. Hansen

ahansen@tlaloc.imta.mx

1 Mexican Institute of Water Technology, Paseo Cuauhnáhuac 8532, 62550 Jiutepec, Morelos, Mexico

2 Association of the International Symposium on Sediment Management, ASIMS, IMT, Lille, Douai, France

3 Faculty of Chemical Sciences, Autonomous University of San Luis Potosí, SLP, Mexico
The 6th International Symposium on Sediment Management (I2SM 2018) was organized by the Mexican Institute of Water Technology (IMTA) and the Association for the International Symposium on Sediment Management (ASIMS), and it focused on the evaluation and management of sediments and porous media and was held on June 19-23, 2018, in San Cristóbal de Las Casas, Chiapas, Mexico. This special issue of Environmental Science and Pollution Research includes selected papers presented atI2SM 2018.

I2SM is an International Symposium of Sediment Management launched in 2008 in the city of Lille in the north of France. The aim of this international event is to gather researchers, industrials, and engineers around the transdisciplinary problem of better managing sediments. After the first edition of I2SM in France, this international event was organized in Casablanca (Morocco) in 2010, Alibaug (India) in 2012, Ferrara (Italy) in 2014, and Montreal (Canada) in 2016, and in 2018, it welcomed the participants of I2SM in San Cristóbal de las Casas, Chiapas (Mexico).

During these 10 years, I2SM has reached an outstanding international recognition with participants from over 25 countries. I2SM 2018 covered a broad range of topics as described in the following text.

The session "Advances in sediment management in tropical and subtropical environments" was coordinated by José Luis Arellano, Mexican National Water Commission, and Silke Cram, Institute of Geography at the National Autonomous University of Mexico (UNAM). This thematic session included papers on measurement and evaluation of soil erosion, nutrimental losses in agricultural lands, sedimentation processes, and implementation of techniques of soil erosion and sedimentation control in watersheds, rivers, lakes, and wetlands. The soil erosion and sedimentation are processes related to hydrological phenomena and environmental degradation that affect environmental hydrological services. In tropical and subtropical regions, soil erosion and sedimentation processes are often associated with extreme rainfall and runoff events, soil conditions, steep land slopes, and management practices. All these factors are highly important to 
consider in the sediment management of most Latin American countries.

The topic "Sediment-driven reactions and transport of pollutants in rivers and groundwater", was coordinated by Graciela Herrera, Institute of Geophysics, and Blanca Prado, Institute of Geology, UNAM, and brought together researchers who develop and apply reactive transport modeling (RTM) and decision makers who utilize these models or the results they generate. The objective was to explore the capabilities and growing requirements for data and other information, as well as to identify needs and enhance the future of RTM-based research. Sediment-driven reactions and transport of pollutants is often described by RTM, and it represents the culmination or coming together of theoretical and empirical chemical and physical data to generate both descriptive and predictive models of systems behavior, often for complex, multicomponent, multiphase systems. The requirement for RTM is growing, especially in the fields of carbon storage, unconventional hydrocarbon extraction, mineral exploration, and mine development.

The water-sediment interaction were discussed at hydraulic structures that include a broad variety of applications such as dams, river flood controls, piers, and protection works on rivers such as borders and dikes. The flow around hydraulic structures is complex, three dimensional and highly turbulent with sediment transport. Pier scour is influenced by flow structures, and sediment factors, as the vortices and turbulence structures around the piers, and by sediments in water bodies. Dams in rivers typically cause upstream degradation and downstream erosion. Studies on interactions between hydraulic works, water, and sediment, aim at understanding the effects of hydraulic structures on natural systems. Laboratory experiments, field campaigns, physical, and numerical modeling, analysis of occurred events, are carried out to obtain criteria and methods for improving design, construction, operation, and maintenance of hydraulic structures. The session on "Hydraulic works and water-sediment interactions" was coordinated by Joselina Espinoza, Mexican Institute of Water Technology, and Moisés Berezowsky, Institute of Engineering, UNAM.

Sediment monitoring and characterization are activities of major importance for the comprehension of concentrations and dynamics of pollutants and their biogeochemical and ecological processes in water-sediment interfaces in both spatial and temporal dimensions. The availability and behavior of organic and inorganic contaminants, their physical, chemical, and microbiological interactions in water and sediments, and their effects on benthic biota depend importantly on the composition and structure of these matrices. The session "Characterization and monitoring of sediments and porous media" included papers that help understanding the importance of sediment monitoring and characterization in a multidisciplinary perspective in order to provide new insight in this topic as well as novel methodologies and applications, and was coordinated by Nadia Martínez Villegas, Institute of Scientific and Technological Research of San Luis Potosí, Mexico, and Perla Alonso, Mexican Institute of Water Technology.

Another session referred to "Geochemistry at the sedimentwater interface" and was chaired by Ma. Catalina Alfaro, Autonomous University of San Luis Potosí, Mexico, and Mario Villalobos, Institute of Geology, UNAM. The objective was to discuss how exchange of solutes and particles between water and sediments, and prevailing geochemical conditions at the sediment-water interface, affect the diffusion of dissolved oxygen, the internal cycling of nutrients, the chemical stabilization of organic and inorganic pollutants, and the fate and availability of substances for benthic organisms and plants. Before being effectively stabilized and accumulated, pollutants entering surface waters participate in several biogeochemical processes, and many are partially accumulated in sediments, that may then act as secondary contaminant sources, by releasing these substances through processes such as molecular diffusion, particle resuspension, bioturbation, and bioirrigation. Among these processes, the diffusion fluxes at the sediment-water interface may control the magnitude and direction of geochemical processes, affecting the cycles and the environmental fates of nutrients and pollutants. It is therefore important to understand the extent of these processes during implementation and assessment of sediment remediation actions.

The session on "Remediation of contaminated sites: natural attenuation, processing, and reuse", was coordinated by Ma. Teresa Alarcón-Herrera, Center for Research on Advanced Materials, Mexico, and Víctor Luna-Pabello, Faculty of Chemistry, UNAM. It was discussed how advanced practices based on new technologies, improved processes, and evolving science allow to clean up contaminated sediments in a more efficient and sustainable manner while achieving one of the challenges to protect human health and the environment. Natural attenuation is rapidly becoming a widely used approach to manage sediment contamination by hazardous substances caused by accidents or leaks, including mining wastes, industrial, and hazardous waste sites, and landfills. This symposium session brought together parties from all aspects of the sediment remediation community, to exchange ideas and experiences on the management of water and sediment, including methodologies to evaluate pollution problems, to estimate risks to human health and ecosystems, mathematical modeling and application of remediation strategies and approaches.

The role of the industry in the management of sediments was discussed in the session "Perspectives from the private industry", coordinated by Margarita Eugenia Gutiérrez, Faculty of Chemistry, UNAM, and Yann René Ramos, Autonomous University of Guanajuato, Mexico. Every year, rivers and other water bodies are impacted by industrial 
pollutants, representing a potential risks for aquatic life and for sediment and soil quality when affected by river floods and deposits of dredged sediments. The perspectives of metallurgical and mining industries on the management of affected sediments vary widely from one country to another, prevailing two different visions: (i) the fulfillment of regulations or assessment evaluations and (ii) case studies, which apply recent engineering developments to protect populations and resources. The environmental risk is related not only to the behavior of hazardous substances, but also to environmental vulnerability, including human population. The environmental fate of pollutants and the exposure paths are mainly dominated by physico-chemical processes in water and sediment, and the prevailing geochemical conditions. Therefore, multidisciplinary scientific studies play a significant role in sediment management studies. The points of view of relevant stakeholders, like the industry, regarding the different options to properly manage sediments, can help develop environmental regulations and policies, as well as progress-related management programs.

Oil spills, ships accidents, ruptures in transport lines, natural seeps and urban water discharges, introduce raw petroleum and its by-products in marine and coastal areas, where the final destination of these pollutants is the sediment. The more conspicuous examples are the spills of the Ixtoc-I well in the Bay of Campeche, Mexico, and the Macondo well in Lousiana, USA, that both occurred in the Gulf of Mexico. Once the oil is trapped in sediments, it remains there for long time periods, being a risk for benthic and marine organisms interacting with them, and affecting local fisheries. Other large spills have occurred around the world such as in Alaska USA; Spain, and Saudi Arabia. The management and regulations of such pollution vary for different countries and depend on the enforcement of national laws and/or regional agreements. In the session "Contamination of sediments by oil spills: current situation, management, and regulations" coordinated by Alfonso V. Botello, Institute for Limnology and Marine Sciences, UNAM, the dynamics of oil spills and difficulties related to the remediation of contaminated sediments was discussed as well as the lack of action to define regulations for management and enforcement to assure effective clean-up procedures.

The session "Sediments and environmental regulation" followed up the previous discussion. Dealing with sediments is becoming an increasingly urgent task due to the importance of changing natural processes and increasing impacts of anthropogenic activities. In river basins, it is important to preserve connectivity among ecosystems as well as between riverbeds and flooded areas. Sediment transport and deposition are limiting factors for the conservation of wetlands due to the importance of these solids as substrate, nutrients source, and water residence areas during floods. Dams have interrupted sediments fluxes and dredging is an increasing activity worldwide, with effects that are barely known and regulated. Besides, while solving hydrological cycles by mimicking temporal and historical variations through environmental flows, registration of sediments are only occasional at hydrometric gauges, and it is therefore not possible to identify patterns, alterations and trends in their transport. Sediments as means of transportation, transformation and final fate of pollutants are issues of great concern and advances in modeling and regulation are of benefit in this context. Examples on guidelines, approaches and regulations were discussed to help advancing in this topic, which is still unsolved in many parts of the World. The coordinators of this session were Ma. Antonieta Gómez and Pilar Saldaña, Mexican Institute of Water Technology.

In "Historical reconstruction of contaminant loadings in sediments" chaired by Vinicio Macias, Autonomous University of Baja California, Mexico, and Anne M. Hansen, Mexican Institute of Water Technology, the analyses of sediment cores obtained from water bodies were presented as a powerful tool to reconstruct historical changes in concentrations and resulting exposure to contaminants. Sediment cores obtained under conditions such as fine-grained sediments, non-disturbed by physical or biological perturbations are good candidates to determine the historical events of pollutants deposition and accumulation. Pollutants are transported from their sources to water bodies and to highaltitude and latitude regions due to the global distillation or "grasshopper effect", as (semi)volatile chemicals are transported from warmer to colder regions of the Earth, such as polar regions and high mountains. Here they accumulate in ice or sediments that act as destination for such contaminants. Since no permanent sediments monitoring programs have been implemented in many countries, there are no formal inventories of pollutants or evaluation of their exposure risks. However, ice and sediments are excellent matrices for monitoring of historical contamination through sampling and characterization of sediment cores.

Finally, among the main challenges during water and wastewater treatment, the management of produced sludge was addressed. The sustainability and economic feasibility of water and wastewater treatment plants are strongly impacted by the technologies used for sludge management. In the twenty-first century conception, the sludge should be considered as a raw material to produce added-value products, such as fertilizers, soil conditioners, renewable energy, among others. The main characteristics of the resulting sludge depend on the composition of water and/or wastewater and the used treatment technology, which in turn determine the possible benefit obtained from the sludge. Contributions to this subject were presented, including production of biogas, characterization of pathogens and challenges to reuse of the sludge in agricultural activities, added-value products, and recovery of chemical products. The session "Reuse and management of 
sludge from water and wastewater treatment", was coordinated by Gabriela Mantilla, Mexican Institute of Water Technology, and Guillermo Quijano-Govantes, Institute of Engineering, UNAM.

As result of the discussions on these various topics during I2SM 2018 it was concluded that it is urgent to relate and close the gabs between scientific knowledge, practice and legislation regarding generation, reuse, final disposal, ecology and quality of sediments.

This special issue in Environmental Science and Pollution Research does not fully reflect the diversity and creativity of ideas and new insights that were shared at I2SM 2018. However, as editors we hope that the presented papers may prompt scientists from diverse fields in sediment management to participate in I2SM to come. The collected papers show and justify the strong position for evaluating and managing sediments and porous media.

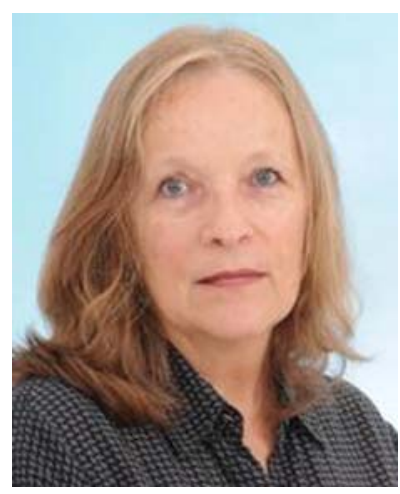

Anne M. Hansen is researcher at the Mexican Institute of Water Technology and she teaches courses and has been advisor on more than 30 undergraduate and graduate theses, mainly in the disciplines of earth sciences and environmental engineering at the National Autonomous University of Mexico (UNAM). Over the last decades, Dr. Hansen has dedicated her research to environmental chemistry and engineering. Her work includes characterization of pollution problems and elaboration of concepts for restoration of soils, sediments, and water bodies. She examines contaminant attenuation mechanisms, and develops and applies models that describe the interaction of pollutants and their distribution in water, sediment, and soil systems. Dr. Hansen has participated in more than 60 research projects, she has published over 90 scientific papers and 30 book chapters. During 2020-2022 she is president of Mexico's Chapter of Interpore and she is coordinating the Sediment Initiative of the Mexican Committee of UNESCO's International Hydrological Programme (CONAMEXPHI).

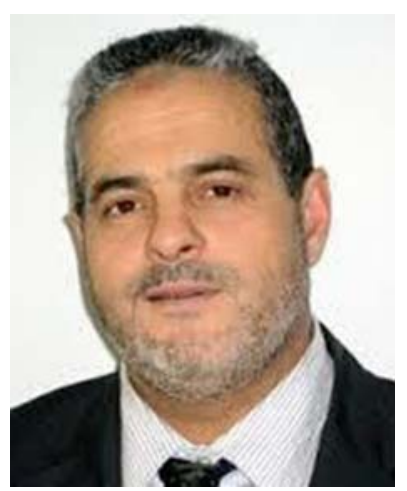

ABRIAK Nor-Edine holds a PhD in Mechanics and a H.D.R. in Mathematical Science; he is Associate Professor at the University of Sherbrooke, Canada, and Professor at IMT Lille-Douai School, France. Since 1993, Prof. Abriak has organized twenty international events in France and abroad and, since 2008, he is President of the Association of the International Symposium on Sediment Management that has held six symposia with participants from 25 countries. Prof. Abriak is Professor of the first national industrial chair on sediments (EcoSed) funded by industrial and institutional partners and that counts with a two million Euro budget. Prof. Abriak's research is devoted to solid mechanics and particularly to granular media from waste, marine, and river sediments, and soil mechanics. Since 1991 he has supervised $39 \mathrm{PhD}$ theses and another 10 theses are in progress. Abriak is the author of 114 articles in peer-reviewed journals and 166 communications in proceedings of congresses and symposia carried out in 35 countries worldwide. He has also participated in various books on sediments and waste.

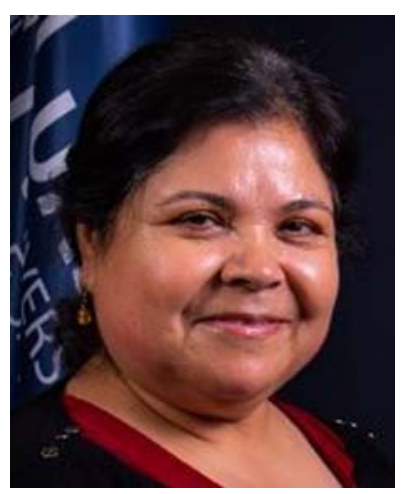

Ma. Catalina Alfaro de la Torre is a full-time professor and researcher at the Faculty of Chemical Sciences at the San Luis Potosí Autonomous University (UASLP) and member of Mexico's Researchers National System (Level I). Her research interests are related to biogeochemistry of trace elements in natural aquatic ecosystems, water quality, and recently, phytoremediation to treat water polluted with metals, nutrients, and pharmaceuticals. Dr. Alfaro holds a $\mathrm{PhD}$ in Water Sciences at the National Institute for Scientific Research - Water Center (INRS-Eau), University of Quebec, Canada. She has supervised 37 undergraduate and graduate theses, and from 2009 to 2015 she represented UASLP in the International Network of Universities of the Center for Natural Resources and Development (CNRD) based at the University of Cologne, Germany. Since 2017, Dr. Alfaro participates in Mexico's National Water Quality Index Network (INCA). 